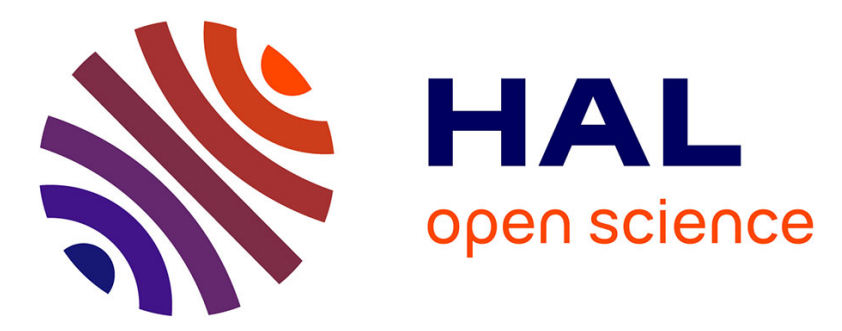

\title{
Communiqué on veering wind effects on scatterometry from the sea-surface
}

\author{
Larry Bliven, Valérie Billat, Piotr Sobieski, A. Guissard, Hubert Branger, \\ Jean-Paul Giovanangeli
}

\section{To cite this version:}

Larry Bliven, Valérie Billat, Piotr Sobieski, A. Guissard, Hubert Branger, et al.. Communiqué on veering wind effects on scatterometry from the sea-surface. Proceedings of IGARSS '94 - 1994 IEEE International Geoscience and Remote Sensing Symposium, Aug 1994, Pasadena, United States. pp.954-956, 10.1109/IGARSS.1994.399311 . hal-00853844

\section{HAL Id: hal-00853844 \\ https://hal.science/hal-00853844}

Submitted on 26 Feb 2021

HAL is a multi-disciplinary open access archive for the deposit and dissemination of scientific research documents, whether they are published or not. The documents may come from teaching and research institutions in France or abroad, or from public or private research centers.
L'archive ouverte pluridisciplinaire HAL, est destinée au dépôt et à la diffusion de documents scientifiques de niveau recherche, publiés ou non, émanant des établissements d'enseignement et de recherche français ou étrangers, des laboratoires publics ou privés. 


\title{
Communiqué on Veering Wind Effects On Scatterometry From The Sea-Surface
}

\author{
L Bliven ${ }^{1}$, V Billat ${ }^{2}$, P Sobieski ${ }^{3}$, A Guissard ${ }^{3}$, H Branger $^{4}$ and J-P Giovanangeli $^{4}$
}

\author{
${ }^{1}$ NASA/Goddard Space Flight Center \\ Laboratory for Hydrospheric Processes \\ Wallops Island, VA 23337 USA \\ fbliven@gsfcmail.nasa.gov \\ ${ }^{3}$ Université Catholique de Louvain \\ Département d'Electricité \\ B-1348 Louvain-la-Neuve, Belgium \\ sobieski or guissard@tele.ucl.ac.be
}

\author{
${ }^{2}$ University Space Research Association \\ Goddard Space Flight Center \\ Greenbelt, MD 20771 USA \\ vb@sausses.cica.fr
}

\author{
${ }^{4}$ Institut de Mécanique Statistique de la Turbulence \\ 12 Av Général Leclerc \\ Marseille, France \\ branger or gio@castor.univ-mrs.fr
}

\begin{abstract}
To characterize scatterometer returns from the sea-surface near meteorological fronts, we investigated microwave scattering from seas in which long-waves are at oblique angles to shortwaves. We simulate the effects of veering winds on a C-band scatterometer by using models in which the short-waves align with the wind-friction velocity $u_{\text {., }}$ but the long-waves are at oblique angles to the $u$. direction. As the oblique angle increases, tilt effects due to the long-waves led to unusual scan patterns with reduced azimuthally-averaged radar cross-sections $a_{0}$.
\end{abstract}

Keywords: fronts, wind and scatterometry.

\section{INTRODUCTION}

Scatterometer backscattered power data are typically useful to infer wind vectors by analysis of normalized radar-cross-section scans $\sigma^{\circ}(\phi)$, where $\phi$ is the azimuthal viewing angle. For suitable steady conditions, wind-wave distributions of the sea-surface are symmetric with respect to the average wind-direction, so azimuthal scans of $\sigma^{\circ}$ are well described by three-term Fourier cosine models. Steady winds, however, do not persist indefinitely because weather conditions are nonstationary, with notable gradients near meteorological fronts and major cyclones. Short waves rapidly adjust to the local wind conditions but the relaxation-time for long-waves is prolonged; consequently, wavedistributions are not always symmetric with respect to the local wind direction. Thus for veering winds, the energy-containing long-waves are not aligned with the wind vector and unfortunately there is a dearth of field measurements to characterize $\sigma^{\circ}(\phi)$. If operational scatterometer algorithms do not account for these circumstances, there is a possibility of increased errors in wind vector estimates in regions where the weather is changing. Fronts are of considerable meteorological and oceanic interest, so it is important to understand and to monitor air-sea interaction processes in these areas. The objective of this paper is to present results of numerical simulations that we conducted to assess the likely effects of veering winds.

Remote sensing studies have not addressed how these factors affect wind estimates, so we conducted a numerical experiment with a C-band scatterometer. Sea-surface models and scattering computations are reviewed prior to reporting the findings. This analysis reveals that long-waves at oblique angles to short windgenerated waves may contribute to considerable errors in wind vectors inferred from scatterometer data.

\section{FORMULATION}

By examination of data and numerical models (Hasselman et al. 1980, Günther et al. 1981, Allender et al. 1983, Holthuijsen et al. 1987, Young et al. 1987, Van Vledder and Holthuijsen 1993, Quanduo and Komen 1993), we find that a congruous description emerges. Assume that homogeneous steady winds are the existing conditions, when suddenly the wind shifts, without changing speed, to a different direction. High frequency waves are closely coupled to the air-boundary layer and they adjust quickly, order of minutes, to new conditions; however the relaxation time for low frequency waves is on the order of hours. So by 'veering' or 'rapidly turning' winds, we mean that the wind direction changes by a significant amount in an interval that is short compared to that required for complete angular relaxation of the entire wave-field. Two regimes are observed: a small shift regime and a large shift regime. In the large shift regime, the wind direction rotates by more than $\sim 60$ to $90^{\circ}$ and a new independent wave system is generated following classical trends, while the preexisting wave system dissipates. This study considers just the small shift regime, in which the wind rotates by less than $\sim 60$ to $90^{\circ}$ and the existing long-wave spectrum slowly rotates to the new wind direction. High-frequency waves quickly align with the effective wind stress; nonlinear interactions siphon energy away from the new wave system (therefore retarding development of a secondary peak) and transfer energy to the preexisting long-wave system; and long-waves lose energy through whitecapping. Due to the asymmetric energy gains by radiative effects and energy losses due to dissipation, the longwave system slowly rotates toward the new wind direction. The rotational relaxation time is approximately equal to the development time for fully-developed seas by comparable winds; the rotational relaxation-time, however, is sensitive to wave-age (shorter for fresher seas). Therefore in small shift cases, spectral evolution due to veering winds is rapid adjustment of short waves to the new wind direction and subsequent turning of long-waves.

The UCL simulator was used in this study to compute backscattered microwave power values for a C-band $(5.3 \mathrm{GHz})$ scatterometer. This software was developed to aid in altimeter 
and scatterometer investigations and it is thoroughly documented by Sobieski et al. (1986); concisely reviewed by Guissard et al. (1994) and Sobieski et al. (1994); and particular features reported by Baufays et al. (1988 a\&b), Guissard et al. $(1986,1987,1989)$ and Sobieski et al. (1991, 1993). Maxwell's equations are the fundamental equations of electromagnetic theory, which is the basis for these estimates of backscattered microwave power from wind-generated surface waves. As usual, the UCL simulator uses composite surface theory, which was developed to deal with the large surface displacements found in ocean waves. A thorough review of this approach is presented by Plant (1990). Although various approximations are required, an important one is that for incidence angles between 20 and $70^{\circ}$, the primary effect of the large-scale surface is simply to tilt the small-scale structure which backscatters according to first-order Bragg theory. Guissard (1993) clanified differences between sea-surface models used for wave propagation studies and models used for scattering studies. There is no sea-surface model that is universally accepted as the standard for naturally occurring winds and seas. We modified the Bjerkaas-Riedel (1979) model to account for veering winds.

\section{RESULTS}

Let's appraise situations in which the wind changes direction, with speed unchanged. Due to geometrical symmetry, clockwise and counterclockwise veering winds yield scatterometric scans that are mirror images, so we present only counterclockwise wind-shifts. Figures 1 and 2 are for C-SCATT at $30^{\circ}$ incidence angle and $\mathrm{VV}$ polarization.

For $\mathrm{u}^{*}$ ranging from 15 to $75 \mathrm{~cm} \mathrm{~s}^{-1}$, we computed azimuthal scans with the oblique angle $\Omega$ ranging from 0 to $55^{\circ}$, by $5^{\circ}$. Figure 1 presents a typical example for $\mathrm{u}^{*}=30 \mathrm{~cm} \mathrm{~s}^{-1}$, which corresponds to moderate surface winds of $\sim 8 \mathrm{~m} \mathrm{~s}^{-1}$. The scatterometer points upwind for $\phi=0^{\circ}$ and countenclockwise veering winds appear as clockwise rotations of long-waves. The scans show that (a) $\sigma$ decreases as the veering angle increases, (b) maxima are rotated away from the wind axis and toward the long-wave axis and (c) at large veering angles, a regime exists with more than two maxima per scan.

To assess the size of wind speed biases that could occur if an algorithm for fully-developed seas is employed for veering-winds conditions, we compured the relative error of wind speed estimates due to veering-winds as

$$
\Delta=\frac{u_{*}(\Omega)-u_{*}}{u_{*}}
$$

where $u_{.}(\Omega)$ is the friction velocity inferred by using a baseline algorithm developed for $\Omega=0^{\circ}$, and input $\mathrm{a}_{0}$ from a veering-wind azimuthal scan. We summarize typical results in figure 2 , which shows the relative error increases more rapidly for higher winds. Typical design specifications call for $<10 \%$ error in wind estimates, consequently these errors are usually less than design objectives for $\Omega<\sim 15^{\circ}$. On the other hand, at larger angles the friction velocity estimates are grossly underestimated. Notice the reduction of $a_{0}$ can be large enough that a scan might be interpreted as representing calm wind or instrumental noise.

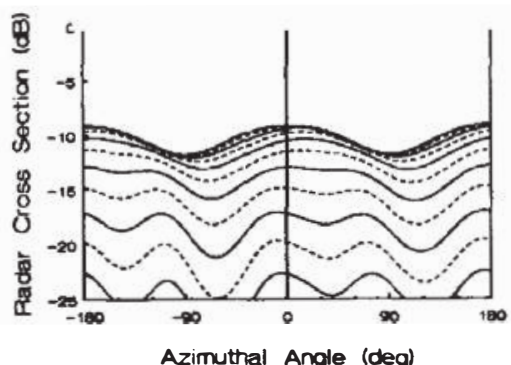

Figure 1. Anomalous effects due to veering winds on C-SCATT scans: reduced power levels and misalignment of maxima.

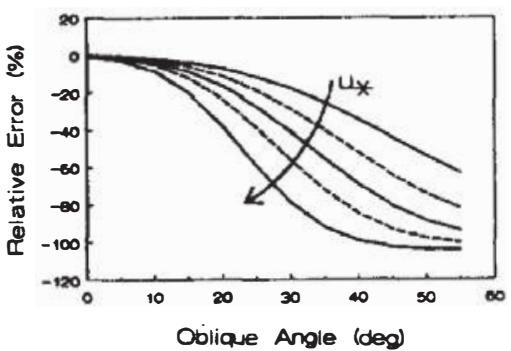

Figure 2. Biases of wind speed estimates due to veering winds.

\section{SUMMARY}

This study provides an assessment of veering wind effects on wind estimates from scatterometry of the sea-surface. Results from the numerical experiment with a $\mathbf{C}$-band scatterometer reveal that veering winds reduce backscattered power levels and alter the shape of azimuthal scans. Fortunately if the veering angle is less than $\sim \pm 15^{\circ}$, the errors due to veering winds should be within typical design specifications ( $\pm 10 \%$ for magnitude). If on the other hand $\pm 15^{\circ}<\Omega< \pm 55^{\circ}$, the effects of veering winds are dramatic and non-negligible because the backscattered power is significantly reduced and there is likely to be more uncertainty in deriving the stress direction. Moreover, power levels may be 
so low in some extreme cases, that inversion algorithms will indicate data drop-out. This serendipitous effect might actually be useful for locating fronts. The general trends appear regardless of long-wave steepness or wind speed, so when weather patterns cause a shift in wind direction greater than $\sim \pm 15^{\circ}$ (on a time scale that is short compared to the long-wave relaxation-time), results from standard scatterometer data reduction algorithms should be used with prudence.

These findings are dependent upon model assumptions, as is always the case for numerical experiments. Although we used sea-surface models that are in accord with present qualitative descriptions, more detailed measurements of sea-surface morphology for veering winds would certainly be helpful to guide and validate further numerical model development. Refinement of scattering calculations and data inversion techniques will be dependent upon a better understanding of (a) air-sea coupling processes (b) long-wave slope probability density distributions and (c) wave-wave interaction mechanisms. In this vein, a recent study by Geernaert et al. (1993) presents progress toward understanding the directional attributes of the ocean surface wind stress vector because it provides in situ measurements which are evidence that the stress vector direction is altered (stress vector and wind vector are non-aligned) due to long-wave effects pursuant to veering-winds. The role of various physical mechanisms that might contribute to this deviation is, however, still unsettled; so further research is needed to model momentum flux at the air-sea interface with respect to the wind-profile and sea-surface characteristics. It is suggested that veering-wind studies also include microwave scattering measurements so that weather fronts can be accurately monitored globally.

\section{ACKNOWLEDGMENTS}

Thanks to our colleagues at UCL, IMST and NASA who participated in this research. Parts of the scattering model were developed at UCL under contracts with the European Space Agency (ESA), whose financial support is acknowledged. Support was also provided by the NASA Mission to Planet Earth Program; the Office of Naval Research, Marine Boundary Layer Advanced Research initiative of the Remote Sensing Program and the Physical Oceanography Program; and the Centre National de la Recherche Scientifique. Claude Klapisz of DEA de Méthode physique en télédetection, L'Université de Paris VII, helped to coordinate and fund this collaboration with V. Billat.

\section{REFERENCES}

[1] Allender, J.H., J. Albrecht and G. Hamilton. "Observations of directional relaxation of wind sea spectra.", Joumal of Physical Oceanography, 13, 1519-1525, 1983.

[2] Baufays, C., A. Guissard and P. Sobieski. "A three degreeof-freedom description of the ocean surface for microwave remote sensing of wave height and wind friction velocity." Proceedings of the 4th International Colloquium on Spectral Signatures of Objects in Remote Sensing, Aussois, France, ESA SP-287, 55-61, 1988a.

[3] Baufays, C., A. Guissard and P. Sobieski. "Application of a new description of ocean surface spectrum to microwave remote sensing." 13th General Assembly of the European Geophysical Society, Bologna, Italy, 23p., 1988b.

[4] Bjerkaas, A.W. and F.W. Riedel. "Proposed model for the elevation spectrum of a wind-roughened sea surface." Technical Memorandum, JHU/APL 1328, 31p., 1979.
[5] Geernaert, G.L., F. Hansen, M. Courtney and T. Herbers. "Directional attributes of the ocean surface wind stress vector." Joumal of Geophysical Research, 98:C9, 16571-16582, 1993.

[6] Guissard, A. "Directional spectrum of the sea surface and wind scatterometry." International Joumal of Remote Sensing, 14:8, 1615-1633, 1993.

[7] Guissard A., C. Baufays and P. Sobieski. "Sea surface description requirements of electromagnetic scattering calculations." Journal of Geophysical Research, 91:2, 2477-2492, 1986.

[8] Guissard, A. and P. Sobieski. "An approximate model for the microwave brightness temperature of the sea." International Joumal of Remote Sensing, 8:11, 1607-1627, 1987.

[9] Guissard, A., P. Sobieski and C. Baufays. "Microwave remote determination of ocean surface parameters - A preliminary analysis." Microwave radiometry Remote Sensing Applications, edited by P. Pampaloni, 257-269, 1989.

[10] Guissard, A, C. Baufays and P. Sobieski. "Fully and nonfully developed sea models for microwave remote sensing applications." Remote Sensing of the Environment, 1994.

[11] Gunther, H., W. Rosenthal and M. Dunckel. "The response of surface gravity waves to changing wind direction." Joumal of Physical Oceanography, 10, 718-728, 1981.

[12] Hasselmann, D.E., M. Dunckel and J.A. Ewing. "Directional wave spectra observed during JONSWAP 1973." Joumal of Physical Oceanography, 10, 1264-1280, 1980.

[13] Holthuijsen, L.H., A.K. Kuik and E. Mosselman. "The response of wave directions to changing wind directions." Journal of Physical Oceanography, 17, 845-857, 1987.

[14] Ly, L.N. "Effect of angle between wind stress and wind velocity vectors on the aerodynamic drag coefficient at the airsea interface." Journal of Physical Oceanography, 23, 159-163, 1993.

[17] Plant, W.J. "Bragg scattering of electromagnetic waves from the air/sea interface, In Surface Waves and Fluxes, edited by G.L. Geemaert and W.J. Plant (Amsterdam: Kluwer Academic Publishers), 2, 41-108, 1990.

[18] Quanduo, G. and G. Komen. "Directional response of ocean waves to changing wind direction." Journal of Physical Oceanography, 23, 1561-1566, 1993.

[19] Sobieski, P., A. Guissard, C. Baufays, D. Van Hoenacker, AM., Guillaume and A. Van Der Vorst. "Study on propagation and inverse scattering." European Space Agency ESTEC 5285/82 Report, 5 vol, 977p., 1986.

[20] Sobieski, P., A. Guissard and C. Baufays. "Synergic inversion technique for active and passive microwave remote sensing of the ocean." IEEE Transactions on Geoscience and Remote Sensing, 29:3, 391-406, 1991.

[21] Sobieski, P., A. Guissard, C. Baufays and Ph. Siraut. "Sea surface scattering calculations in maritime satellite communications." IEEE Transactions on Communications, 41:10, 1525-1533, 1993.

[22] Sobieski, P., A. Guissard and C. Baufays. "Comparison of microwave signatures for fully and non-fully developed sea models." Remote Sensing of the Environment, 1994.

[23] Van Vledder, G.Ph. and L.H. Holthuijsen. "The directional response of ocean waves to turning winds." Journal of Physical Oceanography, 23:2, 177-192, 1992.

[24] Young, I.R., S. Hasselmann and K. Hasselmann. "Computations of the response of a wave spectrum to a sudden change in wind direction." Journal of Physical Oceanography, 17, 1317-1338, 1987. 